\title{
Child Vaccination and its Impacts on Health and Health Related Matters in Noakhali Region of Bangladesh
}

\author{
Md. Tanvir Haider Tanna ${ }^{1}$, Jamiuddin Ahmed ${ }^{1}$, Pankaj Chandra Debnath ${ }^{1}$, \\ Md. Mizanur Rahman Moghal ${ }^{1}$ and Moynul Hasan ${ }^{2}$ \\ ${ }^{1}$ Depertment of Pharmacy, Noakhali Science and Technology University, Noakhali-3814, Bangladesh \\ ${ }^{2}$ Depertment of Pharmacy, Dhaka International University, Banani, Dhaka, Bangladesh
}

\begin{abstract}
This study was conducted to evaluate the rate of vaccination and its impacts on the children in four upazilas which were Noakhali sadar, Begumgonj, Companygonj and Chatkhil of Noakhali district. The study was carried out during the period of November 15, 2011 to December 15, 2011. Data were collected through questionnaire interviews, focus group discussions and cross check interviews. It was found that all interviewed parents of all ages and educational levels are aware about vaccination of their child. The study conducted on the rate of giving vaccines, (Tuberculosis, Polio, DPT, Measles and Hepatitis B) showed serious reactions in a few children after taking vaccine and occurrences of disease after taking the corresponding vaccine. The rate of vaccination in the four upazilas Noakhali sadar, Begumgonj, Companygonj and Chatkhil were found to be 84, 86.6, 75.4 and 82\%, respectively. No serious reactions were found among 120 children in four upazilas. Among thirty, two children suffered from Measles and one from Hepatitis B after taking the vaccine in sadar upazila. Three children suffered from Measles after Begumgonj and one suffered from Measles in Chatkhil. There were no children found to have a disease after taking the corresponding vaccination in Companygonj. Though the rate of vaccination in these areas is not so little the government should take necessary steps to ensure maximum rate of vaccination.
\end{abstract}

Key words: Vaccination, impacts, education level, measles.

\section{Introduction}

A vaccine is a biological preparation, typically containing an agent which resembles a disease-causing microorganism, often made from weakened or killed forms of the microbe and its toxins or one of its surface proteins (Plotkin et al., 2008). Vaccination means the initiation of the immune system of a person, by administering the antigenic material (a vaccine), to develop adaptive immunity to a disease. Vaccination is considered to be the most effective method of preventing infectious diseases, as vaccines are either prophylactic (to prevent or ameliorate the effects of a future infection by any natural or "wild" pathogen), or therapeutic (vaccines against cancer are also being investigated) (Perz et al., 2006). It is also one of the most economical interventions of modern age, against some of the most lethal and debilitating diseases like smallpox, poliomyelitis, influenza etc. (Chowdhury et al., 2003). Though, there were many positive sides of vaccination, the efforts of vaccination have been met with some war of words, from the beginning of their inception, on scientific, ethical, political, medical safety, religious, and other grounds, as it led to health injury in both the developed and developing countries (Bloom et al., 2005). In spite of its several drawbacks, vaccination program has got early success and widespread acceptance, and as a result mass vaccination campaigns have been undertaken, which greatly reduced the incidence of many diseases in many geographic regions (Ghendon et al., 2006).

Childhood vaccination or child vaccination is the process of administering vaccines on children to stimulate their immune systems to develop adaptive immunity to a disease. Significant reduction of child mortality and finding a cost effective way to improve child health, particularly for poor households residing in high-disease prone regions, is the fundamental principle of childhood

Correspondence to: Jamiuddin Ahmed, Tel: 01924516446, E-mail: jamiuddinju@gmail.com 
vaccination (Koenig et al., 2001; Breiman et al., 2004, Brenzel et al., 2006). Childhood vaccination can also be considered as an investment in human capital, with children's health improvements resulting in their high worker productivity and earnings as adults (Fonseca et al., 1996); as vaccination guards not only against a particular disease, but also provides a wide range of health benefits (Contreras, 1989). Although people's awareness has been increased through mass vaccination campaigns, still the child vaccination coverage is far from universal in many developing countries of the world (Ndirangu et al., 2009).

Though Bangladesh is a developing country, it has a long history of vaccinating its population. The government of Bangladesh initiated a modern Expanded Program on Immunization (EPI) in 1979, which was intensified in 1986 with the donor support and involvement of nongovernmental organizations (NGOs) and civil society. Although the government's EPI campaign attained spectacular success quickly, but still Bangladesh is not able to achieve the target of $80 \%$ Universal Child Immunization (Chowdhury et al., 2003). A lot of studies were carried out to estimate the effect of immunization and its impact on childhood mortality (Ruiz et al., 2006; De Silva and Herm, 1991; Jamil et al., 1999) and the results showed that the highest percentage of fully immunized children, aged less than 12 months, was 62 on the year of 1994 (Chowdhury et al., 2003). However, these results are very much frustrating. So, to create evidence on the impact of child vaccination and to identify $\&$ increase the awareness level among the people in the Noakhali region, which is one of the coastal and southeastern districts of Bangladesh having literacy rate of $69.50 \%$ (Noakhali district, 2012) the present study was undertaken.

\section{Materials and Methods}

Study design: Study was conducted to see the impact, sensitivity of the children and awareness on child vaccination to the people of four upazilas of Noakhali district of Bangladesh by collecting both qualitative and quantitative data randomly through a survey using a structured questionnaire as the principal tool. The questionnaire was in two parts. The first part gathered socio-demographic information of respondents such as age distribution, gender, educational status and vaccination rate. The second part collected information on awareness about child vaccination and the occurrence of disease after taking corresponding vaccine in the study area.

Study area: The study was done among the people of Noakhali district dividing in four groups as four upazilas. Noakhali Sadar, Begumgonj, Companygonj and Chatkhil upazila regions were considered as four different study areas during the survey work. The areas were separated on the basis of infrastructure and socio-economic condition of the people of the area. The study areas were selected according to distance, easy travelling, and density of population to survey.

Sample size: A total of 120 families consisting of both parents and one child were included in the study from four different upazillas (30 in each upazilla). Parents were interviewed using specific questionnaire.

Data collection: After preparing the questionnaire, primary data were collected from the target sites during November 15, 2011 to December 8, 2011, 2011. The respondents were asked to verbally answer a structured set of questionnaires. The primary data were collected from the respondents through face-to-face interview. The questions were asked systemically in a very simple manner and the information was recorded on the survey schedule.

Inclusion and exclusion criteria: The respondents (parents of children) who were easily reachable, especially at health institutions and physicians practice places were included. On the other hand, people who were in house, at office and did not cooperate for survey were excluded. In the survey respondents' age, education and awareness level were considered as criteria for inclusion.

Data processing and analysis: At each stage of the survey, data were checked, edited and coded in the field. Data from various sources were coded and entered into a database system using SPSS 16. Preliminary data sheets were compared with the original coding sheets to ensure the accuracy of the data entered. Descriptive method of analysis was used to describe the survey results using means and percentage. Some diagrams were also used for describing the findings.

\section{Result and Discussion}

Information of age, weight, height, body mass index (BMI) and status of vaccination of the children are 
available from this study (Tables 1 and 2). The study also reports the awareness level of the parents of the children of the study area, about immunization in relation to their educational level and age (Table 3). Obtained data regarding different variables are expressed as mean $(95 \%$ confidence interval $[\mathrm{CI}]$ ) (Tables 1 and 2) and quantitative variables as percentages (Table 3 ).

The descriptive analysis of the anthropometric factors showed that the age most of the children of the study area were between the range of 4 to 23 months. Their body mass index was $16.59 \mathrm{~kg} / \mathrm{m}^{2}$, which was similar to the standard value $16.6 \mathrm{~kg} / \mathrm{m}^{2}$.

The study also revealed the status of immunization in the study area. It was clear from the study not $100 \%$ of the children received vaccination for different diseases. Among the 30 children in each upazillaz, the highest number of children was found vaccinated for polio (29.25 \pm 0.50$)$, whereas the lowest number of children was found $19.75 \pm 2.63$, who were vaccinated for hepatitis B virus.

The present study also tried to collect information on the occurrence of disease after taking corresponding vaccine and the obtained results were represented as the figure 1. There were slight variations about the information on occurrence of disease after taking corresponding vaccine found in the respective study areas. In the study site Companygonj no complication found about the occurrence of disease after taking corresponding vaccine. On the study area Noakhali sadar 1 child was found to be attacked with hepatitis B. Complication with measles in Noakhali sadar, Begumgonj and Chatkhil were found to be 2, 3 and 1, respectively.

Table 1. Descriptive analysis of the anthropometric factors.

\begin{tabular}{lcccc}
\hline \multirow{2}{*}{ Variables } & \multicolumn{2}{c}{ Respondents $(120)$} & \multicolumn{2}{c}{ Range } \\
\cline { 2 - 4 } & Mean \pm SD & $95 \%$ CI & Minimum & Maximum \\
\hline Age (months) & $13.23 \pm 5.88$ & $11.03-15.43$ & 4.00 & 23.00 \\
Body weight $(\mathrm{kg})$ & $7.85 \pm 2.76$ & $6.82-8.88$ & 2.86 & 11.75 \\
Height (inches) & $27.42 \pm 4.43$ & $25.76-29.07$ & 18.60 & 33.70 \\
BMI $\left(\mathrm{kg} / \mathrm{m}^{2}\right)$ & $16.59 \pm 8.60$ & $13.38-19.801$ & 9.86 & 51.61 \\
\hline
\end{tabular}

Table 1. Awareness level among parents of the children of the study area.

\begin{tabular}{|c|c|c|c|c|}
\hline \multirow[t]{2}{*}{ Parameter } & & \multicolumn{2}{|c|}{ Respondents } & \multirow{2}{*}{$\begin{array}{c}\text { Chi Square (d.f.) } \\
\text { P-value }\end{array}$} \\
\hline & & Female (\%) & Male $(\%)$ & \\
\hline \multicolumn{5}{|l|}{ Education } \\
\hline \multirow[t]{2}{*}{ Illiterate } & Aware & 5.55 & 11.11 & $0.400(1)$ \\
\hline & Unaware & 44.44 & 38.89 & 0.527 \\
\hline \multirow[t]{2}{*}{ Can sign } & Aware & 8.33 & 12.5 & $0.253(1)$ \\
\hline & Unaware & 37.5 & 41.67 & 0.615 \\
\hline \multirow[t]{2}{*}{ Primary level } & Aware & 18.18 & 27.27 & $1.467(1)$ \\
\hline & Unaware & 31.82 & 22.73 & 0.226 \\
\hline \multirow[t]{2}{*}{ S.S.C. } & Aware & 34.72 & 41.67 & $1.925(1)$ \\
\hline & Unaware & 15.28 & 8.33 & 0.165 \\
\hline \multirow[t]{2}{*}{ H.S.C and above } & Aware & 47.56 & 48.78 & $0.346(1)$ \\
\hline & Unaware & 2.44 & 1.22 & 0.556 \\
\hline \multicolumn{5}{|l|}{ Age } \\
\hline \multirow[t]{2}{*}{$<20$} & Aware & 3.85 & 7.69 & $3.630(1)$ \\
\hline & Unaware & 73.08 & 15.38 & 0.057 \\
\hline \multirow[t]{2}{*}{$\geq 20$ to $<30$} & Aware & 21.21 & 27.27 & $0.073(1)$ \\
\hline & Unaware & 24.24 & 27.27 & 0.787 \\
\hline \multirow[t]{2}{*}{$\geq 30$ to $<40$} & Aware & 31.37 & 45.10 & $0.003(1)$ \\
\hline & Unaware & 9.80 & 13.72 & 0.956 \\
\hline \multirow[t]{2}{*}{$\geq 40$} & Aware & 21.74 & 56.52 & $3.582(1)$ \\
\hline & Unaware & 13.04 & 8.69 & 0.058 \\
\hline
\end{tabular}


Table 3. Status of child vaccination in different upazilas against some diseases.

\begin{tabular}{lcccc}
\hline Variables & \multicolumn{2}{c}{ Respondents $(120)$} & \multicolumn{2}{c}{ Range } \\
\cline { 2 - 5 } & Mean \pm SD & $95 \%$ CI & Minimum & Maximum \\
\hline Tuberculosis & $25.75 \pm 1.26$ & $23.75-27.75$ & 24.00 & 27.00 \\
Polio & $29.25 \pm 0.50$ & $28.45-30.04$ & 29.00 & 30.00 \\
DPT & $25.50 \pm 1.291$ & $23.44-27.55$ & 24.00 & 27.00 \\
Measles & $22.75 \pm 2.06$ & $19.47-26.03$ & 20.00 & 25.00 \\
Hepatitis B & $19.75 \pm 2.63$ & $15.56-23.93$ & 16.00 & 22.00 \\
\hline
\end{tabular}

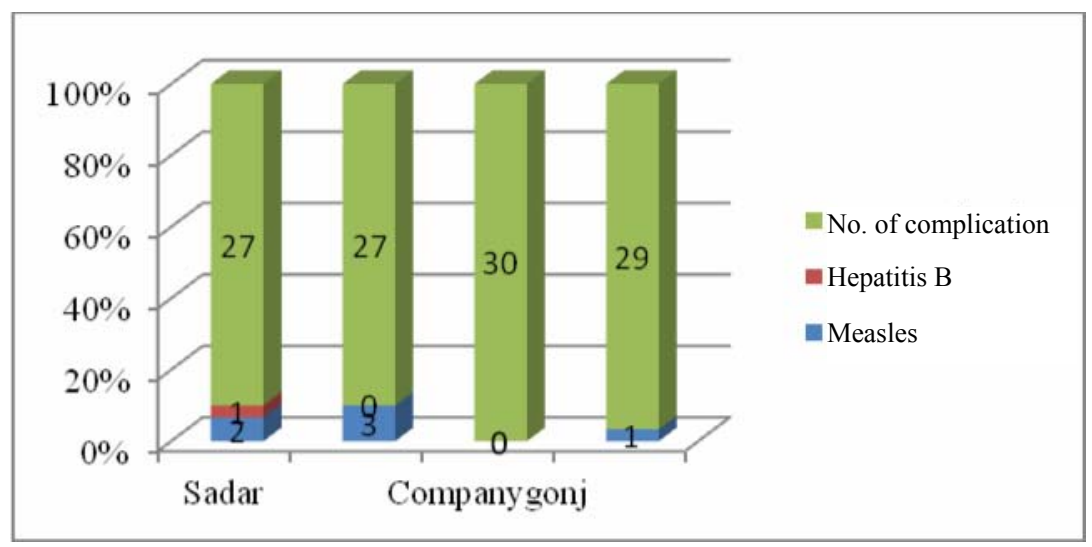

Figure 1. Occurrence of disease after taking corresponding vaccine.

One of the most important findings of the present study was the level of awareness among the parents about child vaccination. In the study we tried to correlate the educational level and age with the awareness level of the parents of the child in the study area (Table 3).

\section{Conclusion}

The most cost effective invention of modern science is vaccination which provides protection against various deadly and incapacitating diseases. A vaccine is weak or killed bacteria that are injected into children to make their body prone to this disease, and help the body fight. Many life-threatening illnesses that once were responsible for killing thousands of children are now preventable by vaccination (Vaccine \& Immunization, 2012). Vaccinating our children not only ensures their safety but also their future to come (Vaccine \& Immunization, 2012). Without vaccinations, infectious diseases would have taken over the world.

Bangladesh has achieved immense success in vaccination. Although $80.2 \%$ vaccination rate was achieved in 2011 still we have long run to go. In our study it is evident that education level as well as age of parents play very important roles in understanding the need of necessity of vaccination. Parents who are illiterate or can barely sign are unaware of benefits from vaccination. Awareness increases with the increase of education. Age also affects awareness to vaccination. Parents, less than 20 years of age, are most unaware of vaccination.

This study may be considered as representative of the other regions of Bangladesh. Government must take initiative to educate people about vaccination and its importance. Active participation of the community members in this process will result in better vaccination awareness and health empowerment.

\section{References}

Bloom, David E.; Canning, David and Weston, Mark 2005. The Value of Vaccination. World Economics, 6, July-Sep.

Breiman, R., Streatfield, P., Phelan, M., Shifa, N., Rashid, M., and M. Yunus 2004 Effect of infant immunisation on childhood mortality in rural Bangladesh: analysis of health and demographic surveillance data. Lancet, 364, 22042211. 
Brenzel, L., Wolfson, L.J., Fox-Rushby, J., Miller, M. and Halsey, N.A. 2006. Vaccine-Preventable Diseases. In: Disease Control Priorities in Developing Countries. D.T. Jamison, J.G. Breman, A.R. Meashamet et al (Eds.). New York, Oxford University Press: 389-412.

Chowdhury, M.R., Bhuiya, A., Simeen Mahmud, S., Salam, A.K.M.A. and Karim, F. 2003. Immunization Divide: Who Do Get Vaccinated in Bangladesh?. J. Health, Population and Nutrition, 21,193-204.

Contreras, G. 1989. Effect of the administration of oral poliovirus vaccine on infantile diarrhoea mortality. Vaccine, 7, 211-2.

De Silva, R., Herm, H., Khan, M. and Chowdhury, JH. 1991. Bangladesh national immunization cluster survey. In: Huq M, editor. Near miracle in Bangladesh. Dhaka: University Press Ltd., pp. 85-96.

Fonseca, W., Kirkwood, B.R., Victora, C.G., Fuchs, S.R., Flores, J.A. and Misago, C. 1996. Risk factors for childhood pneumonia among the urban poor in Fortaleza, Brazil: a case-control study. Bull. World Health Organization, 74, 199-208.

Ghendon Y.Z., Kaira A.N. and Elshina G.A. The effect of mass immunization in children on the morbidity of the unvaccinated elderly. Epidemiol. Infect. 134, 71-78.
Jamil, K et al. 1999. The immunization programme in Bangladesh: impressive gains in coverage, but gaps remain. Health Policy and Planning 14, 49-58.

Koenig, M.A., Bishai, D. and Khan, M.A. 2001. Health interventions and health equity: the example of measles vaccination in Bangladesh. Popul. Dev. Rev. 27, 283-302.

Ndirangu J., Bärnighausen T., Tanser F., Tint K. and Newell M.L. 2009. Levels of child vaccination coverage and the impact of maternal HIV status on child vaccination status in rural Kwazulu-Natal, South Africa. Trop. Med.e Intl. Health, 14, 1383-1393.

Noakhali district, 2011. [http://chittagong.com/noakhali-districtfacts/] [Accessed On: 03/06/13].

Perz J.F., Elm J.L., Fiore A.E., Huggler J.I., Kuhnert W.L. and Effler P.V. 2006. Near elimination of hepatitis B virus infections among Hawaii elementary school children after universal infant hepatitis B vaccination. Pediatr. Ics. 118, 1403-1408.

Plotkin S.A., Orenstein W., Offit P.A. 2008. Vaccines. Elsevier Health Sciences.

Ruiz G.M., Perez S.I., Velazquez F.R., Abate H., Breuer T., Clemens S.C. and Cheuvart B. 2006. Safety and efficacy of an attenuated vaccine against severe rotavirus gastroenteritis, N. Engl. J. Med. 354, 11-12.

Vaccine \& Immunization, 2012. [http://www.cdc.gov/vaccines/ vac-gen/why.htm] [Accessed On: 03/06/13]. 